\title{
FORMULATION DEVELOPMENT AND IN VITRO ANTIOXIDANT AND ANTIDIABETIC EVALUATION OF ERIOBOTRYA JAPONICA BASED SELF NANO EMULSIFYING DRUG DELIVERY SYSTEM
}

\author{
AMRIT PAL SINGH ${ }^{1}$, GOPAL L. KHATIK ${ }^{2}$, VIJAY MISHRA ${ }^{3}$, NAVNEET KHURANA ${ }^{4}$, NEHA SHARMA ${ }^{4}$, MANISH VYAS ${ }^{*}$ \\ 1Department of Ayurveda, School of Pharmaceutical Sciences, Lovely Professional University, Phagwara, Punjab, India 144411, ${ }^{2}$ Department \\ of Pharmaceutical Chemistry, School of Pharmaceutical Sciences, Lovely Professional University, Phagwara, Punjab, India 144411, \\ ${ }^{3}$ Department of Pharmaceutics, School of Pharmaceutical Sciences, Lovely Professional University, Phagwara, Punjab, India 144411, \\ ${ }^{4}$ Department of Pharmacology, School of Pharmaceutical Sciences, Lovely Professional University, Phagwara, Punjab, India 144411 \\ Email: vymanish@gmail.com
}

Received: 11 Mar 2019, Revised and Accepted: 24 May 2019

\section{ABSTRACT}

Objective: The aim of the present study was to develop and characterize self-nano emulsifying drug delivery system (SNEDDS) of methanolic extract of Eriobotrya japonica (Thunb.) Lindl. (E. japonica) leaves. Further in vitro antioxidant and antidiabetic potential of an optimized batch of SNEDDS was explored.

Methods: Oil (Labrafil M 1944 CS), surfactant (Tween 80) and co-surfactant (Transcutol P) were selected on the basis of solubility of the methanolic extract. Twenty-seven batches of SNEDDS were prepared with different compositions of oil, surfactant and co-surfactant. The optimized batch was evaluated for its entrapment efficiency, droplet size, polydispersity index (PDI), zeta potential, transmission electron microscopy (TEM). Further, DPPH assay and $\alpha$-amylase activity were also performed to check the antioxidant and antidiabetic potential of prepared SNEDDS.

Results: The optimized design suggested that 10\% of Labrafil M 1944CS, 30\% of Tween 80 and 60\% of Transcutol P could develop SNEDDS with $208 \mathrm{~nm}$ mean droplet size, 99.64\% drug loading, 0.156 PDI and- $6 \mathrm{mV}$ zeta potential. TEM image confirmed the droplet size less than $100 \mathrm{~nm}$ and the spherical shape of SNEDDS. In vitro antioxidant and antidiabetic activities of SNEDDS revealed the increased efficacy as compared to that of the ascorbic acid and acarbose, respectively.

Conclusion: The optimized batch of SNEDDS was found to improve the antioxidant and antidiabetic efficacy of methanolic extract of E. japonica.

Keywords: SNEDDS, Eriobotrya japonica, DPPH, Antidiabetic, Antioxidant

(C) 2019 The Authors. Published by Innovare Academic Sciences Pvt Ltd. This is an open access article under the CC BY license (http://creativecommons.org/licenses/by/4.0/] DOI: http://dx.doi.org/10.22159/ijap.2019v11i4.33006

\section{INTRODUCTION}

Ethnomedicine is the traditional medical practice of indigenous culture that gave remedial and palliative effects of a complex multi-disciplinary system constituting the use of herbs, spirituality and the natural environment, which have the ability to promote the health and healing potential for humanity. Efficacy of ethnomedicines mainly depends on the presence of pharmacologically active phytoconstituents. Moreover, development in the fields of phytochemistry and phytopharmacology has increased exploration of ethnomedicines for their effective biological attributes [1-4]. However, these phytoconstituents are not permeable to the lipid membranes due to the high molecular weight and low rate of absorption, which ultimately affect the bioavailability and efficacy of the drugs. Apart from this, various drawbacks related to the dose, palatability, stability, and toxicity of the phytoconstituents and their formulations have also been reported. Therefore, recent studies based on the nanotechnology and phytopharmaceuticals have suggested the integration of phytoconstituents and nanotechnology because nanocarriers can efficiently carry such phytoconstituents at the desired site of action inadequate concentration and can be helpful to address the associated drawbacks of the phytomedicines [5].

Recently, the development of self-nano emulsifying drug delivery system (SNEDDS) for herbal drugs has received a lot of attention as a novel approach to overcome drawbacks associated with plant-based medicines. The SNEDDSs are isotropic and thermodynamically stable mixtures of oil, surfactant (HLB>12) and co-surfactant. The SNEDDS can emulsify spontaneously in situ with the contact of gastrointestinal tract (GIT) fluid. The SNEDDS can be an effective alternative for the plant extracts by taking the benefit of lipophilic nature to overcome their drawbacks related to the poor solubility, bioavailability, absorption, palatability, and instability [5].

Eriobotrya japonica (Thunb.) Lindl. (E. japonica), a traditional medicinal plant used to treat diverse pathophysiological conditions is also consumed as a food product in daily life. Generally, it is used in East Asian countries like Japan, China, Korea, India, Nepal, and Pakistan. In India, it is mainly used in various states including Uttar Pradesh, Punjab, and Himachal Pradesh. The traditional healers and Vaidyas use the juice of E. japonica leaves to treat diabetes. The recent studies suggested the diversified pharmacological effects of $E$. japonica including antidiabetic effect [6], neuroprotection [7], cardiovascular health [8], glucose metabolism [9], anti-obesity [10], bone and joint strength [11], anti-inflammatory [12], hormonal activity [13], effects on peripheral organ systems [14] and anticancer activities [15].

The present study was designed to develop and characterize the SNEDDS based ethnomedicine and explore the improved antioxidant and antidiabetic potential of E. japonica.

\section{MATERIALS AND METHODS}

\section{Materials}

Labrafil M 1944 CS, and Transcutol $\mathrm{P}$ were received from the Gattefosse, Mumbai, India as gift samples. Tween 80 and Ethanol were purchased from Loba Chemie (P) Ltd., Mumbai (Maharashtra), India. The double distilled water of USP grade was used throughout the study. The fresh leaves of E. japonica were collected from village Kotla Naudh Singh of district Hoshiarpur (Punjab). The latitude 31.5977701 and longitude 75.8330591 are the geocoordinates of Kotla Naudh Singh village. The leaf sample of E. japonica was authenticated from National Institute of Pharmaceutical Education and Research (NIPER), Mohali with NIPER/2018/AS/3 voucher specimen number.

\section{Preparation of methanolic extract of E. japonica}

Leaves of E. japonica were washed with running tap water and shade dried. Coarse powder of shade-dried leaves was prepared for the extraction using Soxhlet apparatus. The coarse powder (25 g) 
was kept in a thimble and $150 \mathrm{ml}$ of methanol as a solvent was used for the extraction. The process was continued for $24 \mathrm{~h}$ at $65^{\circ} \mathrm{C}$. The extraction was repeated six times. After the continuous extraction process, methanol was evaporated by using a water bath to get the dried extract [16].

\section{UV spectroscopic analysis of the extract}

The dried extract (300 mg) was dissolved in $6 \mathrm{ml}$ of ethanol for the preparation of stock solution having a concentration of $50 \mathrm{mg} / \mathrm{ml}$. Solutions with different concentrations ranging from 10, 20, 30, 40 and $50 \mu \mathrm{g} / \mathrm{ml}$ were prepared from the stock solution by appropriate dilutions and analyzed spectrophotometrically (1601 UV-vis spectrophotometer, Shimadzu, Kyoto, Japan) in the wavelength range of 200-400 $\mathrm{nm}$. The absorbance of standard solutions was measured at $275 \mathrm{~nm} \lambda_{\max }$ and a calibration curve was plotted.

\section{Solubility studies}

For the preparation of SNEDDS, the solubility study was performed using oil (Labrafil M 1944 CS), surfactant (Tween 80) and cosurfactant (Transcutol P) (table 2). A briefly predetermined amount of extract was mixed in oil, surfactant and co-surfactant separately, vortexed for $15 \mathrm{~min}$ and then kept shaken for $3 \mathrm{~d}$ on a water bath at $25{ }^{\circ} \mathrm{C}$. The resulting mixtures were centrifuged at $3500 \mathrm{rpm}$ for 15 min. The supernatants were collected and analyzed using UV-Visible spectrophotometer at $275 \mathrm{~nm}$. The study was repeated in triplicate and mean data was recorded.

\section{Preparation of self-nano emulsifying drug delivery system}

On the basis of solubility of the extract, the oil (Labrafil M 1944 CS), surfactant (Tween 80) and co-surfactant (Transcutol P) were selected and 27 formulations of SNEDDS were prepared by selecting different concentrations of the oil, surfactant and co-surfactant ranging from $10-70 \%$. Each composition was loaded with $150 \mathrm{mg}$ of extract. The resultant mixture was sonicated by using ultrasonicator for $30 \mathrm{~min}$ at $37^{\circ} \mathrm{C}$. Further, the isotropic mixture was diluted with $250 \mathrm{ml}$ of double distilled water and stirred at $100 \mathrm{rpm}$ at $37^{\circ} \mathrm{C}$ using the magnetic stirrer to check the emulsification of the selected oil, surfactant, and co-surfactant. The prepared emulsions were visually evaluated for their relative turbidity. The formation of proper nanoemulsion was determined when uniform dispersion of droplets into the water resulted in transparent milky emulsion whereas immediate coagulation of droplets after stirring resulted in the improper or no formation of the nanoemulsion. The emulsification was assessed by using grading criteria [17]. A ternary phase diagram was prepared for all compositions and SNEDDS area was highlighted [18]. All studies were repeated in triplicate $(n=3)$, with similar observations being made between repeats.

\section{Turbidity measurements}

The turbidity of the prepared emulsions was measured by using Orbeco-Hellige model 966, Orbico Analytical system Inc., Framingdale, New York, USA (table 2).

\section{Entrapment efficiency}

The proportion of encapsulated extract was determined by centrifuging $10 \mathrm{ml}$ of the prepared formulation at $15000 \mathrm{rpm}$ for $180 \mathrm{~min}$ at room temperature. The supernatant collected using micropipette without disturbing the sediment was dissolved in the ethanol to disrupt the vesicles. After proper dilutions, the unentrapped drug was determined spectrophotometrically at $275 \mathrm{~nm}$ [19]. Entrapment efficiency was calculated by the equation below:

$$
\% \text { Entrapment Efficiency }=\left[\frac{\text { Amount of encapsulated drug }}{\text { Amount of total drug }}\right] \mathrm{X} 100
$$

\section{Droplet size and Zeta potential analysis}

The average droplet size, polydispersity index (PDI) and zeta potential of the optimized batch of SNEDDS were measured by Malvern Nano zeta sizer instrument (DTS Ver. 5. 10). The optimized batch of SNEDDS $(0.1 \mathrm{ml})$ was dispersed in $100 \mathrm{ml}$ of water. Further, $1 \mathrm{ml}$ of the aliquot was introduced into a sample cell for the measurement of the droplet size $[18,20]$. The temperature was maintained at $25^{\circ} \mathrm{C}$ and the angle was fixed angle at $90^{\circ}$ during the evaluation.

\section{Transmission electron microscopy}

The size of droplets of the prepared formulation was determined by Transmission electron microscope (H-600, Hitachi, Japan) under 200000X resolution. Briefly, for the preparation of the sample, an optimized batch of the prepared formulations was diluted with 1000 $\mathrm{ml}$ of water to prepare an emulsion. Further, it was stained using 2 $\% \mathrm{w} / \mathrm{v}$ phosphotungstic acid and kept on the copper grids of $400-$ mesh with films for evaluation $[20,21]$.

\section{In vitro antioxidant activity}

The antioxidant activity was determined by the DPPH assay method [22]. Briefly, $200 \mu \mathrm{l}$ of the analytical sample and $800 \mu \mathrm{l}$ of $0.1 \mathrm{M}$ Tris$\mathrm{HCl}$ Buffer (pH7.4) were added in a test tube. Ethanolic DPPH solution $(1 \mathrm{ml})$ was added immediately and test tubes were shaken for 10 seconds. Then, the solution was kept in a dark place at room temperature for $30 \mathrm{~min}$. The absorbance of the solution was measured at $517 \mathrm{~nm}$ [22]. The study was repeated in triplicate. Percentage of inhibition was calculated by using the following formula:

$$
\begin{aligned}
& \text { Percentage inhibition } \\
& =\left[\frac{\text { (Absorbance of control }- \text { Absorbance of sample })}{\text { Absorbance of control }}\right] \times 100
\end{aligned}
$$

\section{In vitro $\alpha$-amylase inhibition assay}

The $\alpha$-amylase $(500 \mu \mathrm{l})$ was added into different dilutions $(0.075$ $0.75 \mathrm{mg} / \mathrm{ml}$ ) of the sample and standard drug. After incubation at 25 ${ }^{\circ} \mathrm{C}$ for $10 \mathrm{~min}, 500 \mu \mathrm{l}$ of $1 \%$ starch solution was added. Again, it was incubated at $25^{\circ} \mathrm{C}$ for $10 \mathrm{~min}$. In the next step, $1 \mathrm{ml}$ DNS reagent was added and kept in a boiling water bath for $5 \mathrm{~min}$. After the selfcooling, add $10 \mathrm{ml}$ of distilled water in each test tube and the absorbance was taken at $540 \mathrm{~nm}$ [22]. The percentage of inhibition was calculated by using the following formula:

$$
\% \text { Enzyme activity }=\left[\frac{\{(\mathrm{A}-\mathrm{C})-\mathrm{T}\}}{(\mathrm{A}-\mathrm{C})}\right] \times 100
$$

Where, $\mathrm{A}, \mathrm{C}$, and $\mathrm{T}$ were the absorbance of negative control, positive control and test sample, respectively.

Percentage of inhibition $=100-\%$ Enzyme activity

\section{RESULTS AND DISCUSSION}

\section{Extraction of $E$.japonica}

The methanolic extract of dried leaves of E. japonica was obtained with the help of the Soxhlet apparatus. The percentage of yields of

\begin{tabular}{|c|c|c|c|c|c|c|c|}
\hline \multirow[t]{2}{*}{ Observations } & \multicolumn{6}{|c|}{ Batch } & \multirow[t]{2}{*}{ Average } \\
\hline & I & II & III & IV & $\mathbf{V}$ & VI & \\
\hline Weight of drug (g) & 25 & 25 & 25 & 25 & 25 & 25 & 25 \\
\hline Volume of solvent (mL) & 150 & 150 & 150 & 150 & 150 & 150 & 150 \\
\hline Yield of extract (\%) & 12 & 9.6 & 9.6 & 11.2 & 11.2 & 12.8 & 11.06 \\
\hline Duration (hours) & 24 & 24 & 24 & 24 & 24 & 24 & 24 \\
\hline
\end{tabular}
different batches were found to be 12, 9.6, 9.6, 11.2, 11.2 and $12.8 \%$, respectively. The average yield of extract was $11.06 \%$ (table 1 ).

Table 1: Observation table of extraction of leaves of $E$. japonica 


\section{UV spectroscopic analysis}

The concentration of the extract was taken $1 \mathrm{mg} / \mathrm{ml}$ for UV spectroscopic determination of the $\lambda_{\max }$, which was observed as 275 $\mathrm{nm}$. It was used to determine the linearity of a serial dilution of the extract. The observed absorbance of UV spectra with respect to different concentration $(10-50 \mu \mathrm{g} / \mathrm{ml})$ was plotted as the standard graph. The observed linear regression equation was found to be $\mathrm{Y}=$ $0.0288 x+0.0751, R^{2}=0.9944$ depicting the linearity (fig. 1 ).

\section{Preparation of self-nano emulsifying drug delivery system (SNEDDS)}

With the help of Labrafil M 1944 CS (oil), tween 80 (surfactant) and Transcutol P (co-surfactant) in different concentrations, 27 formulations of the SNEDDS based on the solubility (table 2) were prepared and observed visually for their self-emulsifying ability (table 3).

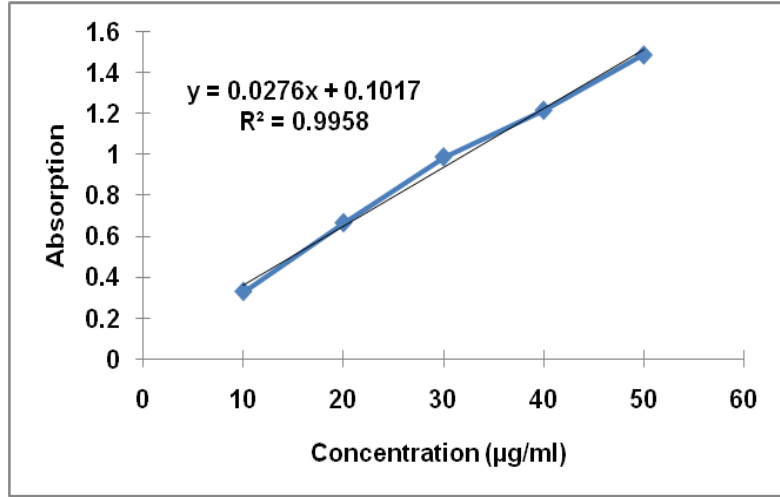

Fig. 1: Calibration curve of methanolic extract of $E$. japonica

Table 2: Solubility profile of $E$. japonica extract

\begin{tabular}{ll}
\hline Vehicle & Solubility (mg/ml) \\
\hline Oil (Labrafil M1944CS) & $14.58 \pm 0.25$ \\
Surfactant (Tween 80) & $8.91 \pm 0.13$ \\
Co-surfactant (Transcutol P) & $8.72 \pm 0.14$ \\
\hline
\end{tabular}

The concentration of extract (150 mg) was kept the same for all the batches. A pseudo-ternary phase diagram was created to identify the region of self-emulsification and concentrations of oil, surfactant and co-surfactant were also optimized for the formulation. The ternary phase diagram of the different batches is shown in fig. 2. Formulation $\mathrm{B}_{1}$ was found clear among all the batches and considered as SNEDDS on the basis of its visual inspection. Batch B10 was found to be transparent and clear but unstable. Creaming was observed in $\mathrm{B}_{2}, \mathrm{~B}_{3}$, $\mathrm{B}_{4}, \mathrm{~B}_{7}, \mathrm{~B}_{8}, \mathrm{~B}_{9}, \mathrm{~B}_{11}, \mathrm{~B}_{12}, \mathrm{~B}_{13}, \mathrm{~B}_{16}, \mathrm{~B}_{17}, \mathrm{~B}_{18}, \mathrm{~B}_{19}, \mathrm{~B}_{20}, \mathrm{~B}_{21}, \mathrm{~B}_{22}, \mathrm{~B}_{25}, \mathrm{~B}_{26}$, and $B_{27}$ while phase separation occurred in $B_{5}, B_{6}, B_{14}, B_{15}, B_{23}$, and $B_{24}$. It was also observed that $10 \%$ of Labrafil M1944 CS is sufficient to solubilize the extract. Fig. 2 showed the ternary phase diagram.

Table 3: Observations of different ratio of oil, surfactant, and co-surfactant

\begin{tabular}{|c|c|c|c|c|c|c|c|}
\hline Batch code & Oil $(\mu \mathrm{l})$ & Surfactant $(\mu \mathrm{l})$ & Co-surfactant $(\mu \mathrm{l})$ & Extract $(\mu \mathrm{l})$ & Water (mL) & Turbidity (NTU) & Inference \\
\hline $\mathrm{B}_{1}$ & 0.1 & 0.3 & 0.6 & 150 & 100 & 2.34 & Clear \\
\hline $\mathrm{B}_{2}$ & 0.2 & 0.27 & 0.53 & 150 & 100 & 16.21 & Creaming \\
\hline $\mathrm{B}_{3}$ & 0.3 & 0.23 & 0.47 & 150 & 100 & 18.49 & Creaming \\
\hline $\mathrm{B}_{4}$ & 0.4 & 0.2 & 0.4 & 150 & 100 & 19.31 & Creaming \\
\hline $\mathrm{B}_{5}$ & 0.5 & 0.17 & 0.33 & 150 & 100 & $>20$ & Cracking \\
\hline $\mathrm{B}_{6}$ & 0.6 & 0.13 & 0.27 & 150 & 100 & $>20$ & Cracking \\
\hline $\mathrm{B}_{7}$ & 0.2 & 0.6 & 0.2 & 150 & 100 & 20.11 & Creaming \\
\hline $\mathrm{B}_{8}$ & 0.2 & 0.7 & 0.1 & 150 & 100 & 16.72 & Creaming \\
\hline $\mathrm{B}_{9}$ & 0.1 & 0.7 & 0.2 & 150 & 100 & 17.93 & Creaming \\
\hline $\mathrm{B}_{10}$ & 0.1 & 0.45 & 0.45 & 150 & 100 & 3.19 & Clear \\
\hline $\mathrm{B}_{11}$ & 0.2 & 0.4 & 0.4 & 150 & 100 & 19.16 & Creaming \\
\hline $\mathrm{B}_{12}$ & 0.3 & 0.35 & 0.35 & 150 & 100 & 17.23 & Creaming \\
\hline $\mathrm{B}_{13}$ & 0.4 & 0.3 & 0.3 & 150 & 100 & 18.87 & Creaming \\
\hline $\mathrm{B}_{14}$ & 0.5 & 0.25 & 0.25 & 150 & 100 & $>20$ & Cracking \\
\hline $\mathrm{B}_{15}$ & 0.6 & 0.2 & 0.2 & 150 & 100 & $>20$ & Cracking \\
\hline $\mathrm{B}_{16}$ & 0.3 & 0.5 & 0.2 & 150 & 100 & 17.38 & Creaming \\
\hline $\mathrm{B}_{17}$ & 0.3 & 0.6 & 0.1 & 150 & 100 & 19.22 & Creaming \\
\hline $\mathrm{B}_{18}$ & 0.4 & 0.5 & 0.1 & 150 & 100 & 16.78 & Creaming \\
\hline $\mathrm{B}_{19}$ & 0.1 & 0.6 & 0.3 & 150 & 100 & 17.38 & Creaming \\
\hline $\mathrm{B}_{20}$ & 0.2 & 0.53 & 0.27 & 150 & 100 & 14.44 & Creaming \\
\hline $\mathrm{B}_{21}$ & 0.3 & 0.47 & 0.23 & 150 & 100 & 15.66 & Creaming \\
\hline $\mathrm{B}_{22}$ & 0.4 & 0.4 & 0.2 & 150 & 100 & 17.69 & Creaming \\
\hline $\mathrm{B}_{23}$ & 0.5 & 0.33 & 0.17 & 150 & 100 & $>20$ & Cracking \\
\hline $\mathrm{B}_{24}$ & 0.6 & 0.27 & 0.13 & 150 & 100 & $>20$ & Cracking \\
\hline $\mathrm{B}_{25}$ & 0.1 & 0.5 & 0.4 & 150 & 100 & 16.85 & Creaming \\
\hline $\mathrm{B}_{26}$ & 0.1 & 0.4 & 0.5 & 150 & 100 & 17.74 & Creaming \\
\hline $\mathrm{B}_{27}$ & 0.1 & 0.2 & 0.7 & 150 & 100 & 18.55 & Creaming \\
\hline
\end{tabular}

\section{Entrapment efficiency}

Entrapment efficiency provides the concentration of the drug entrapped into the carrier. The process was repeated for three times. The average percent entrapment efficiency was found to be $99.63 \%(n=3)$, which indicated that most of the added extract was entrapped in SNEDDS.

\section{Particle size and polydispersity index}

The particle size and PDI of the optimized batch of SNEDDS were determined by differential light scanning (DLS) technique. The average droplet size and PDI of the optimized batch of SNEDDS were found to be in nano-range i.e. $206.0 \mathrm{~nm}$ and 0.156 , respectively (fig. 3). 


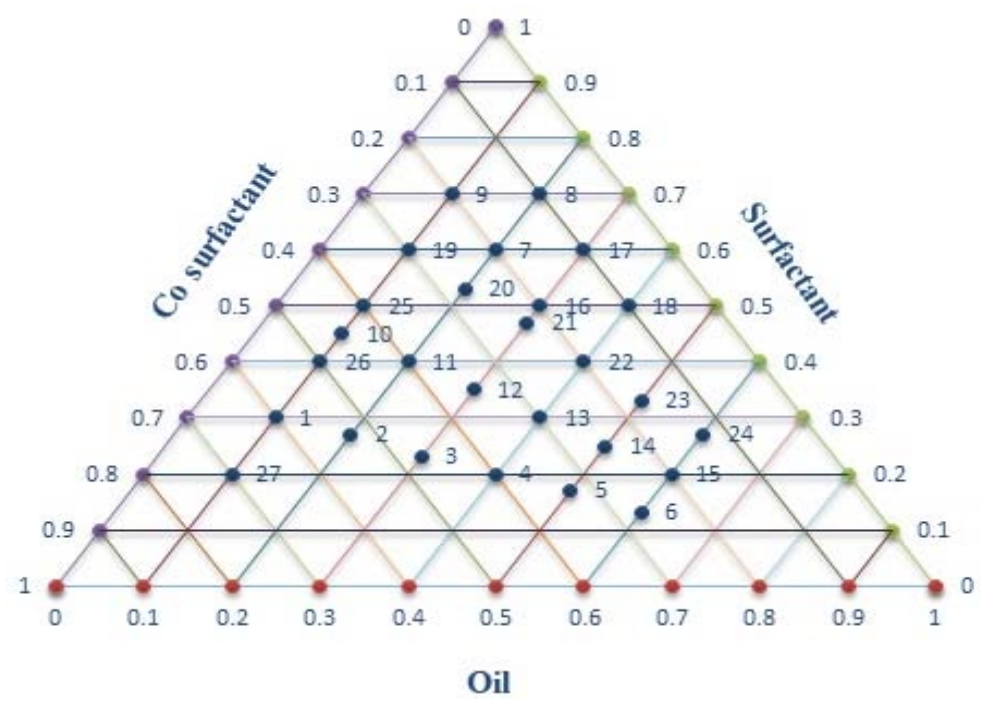

Fig. 2: Ternary phase diagram showing SNEDDS, emulsion and phase

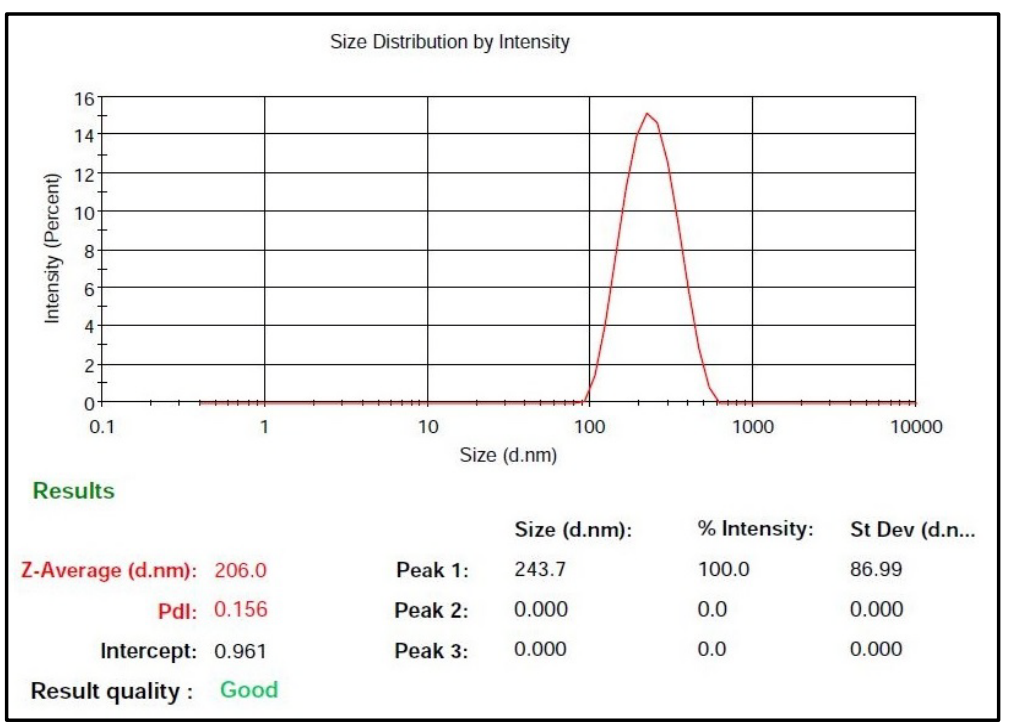

Fig. 3: Particle size and polydispersity index

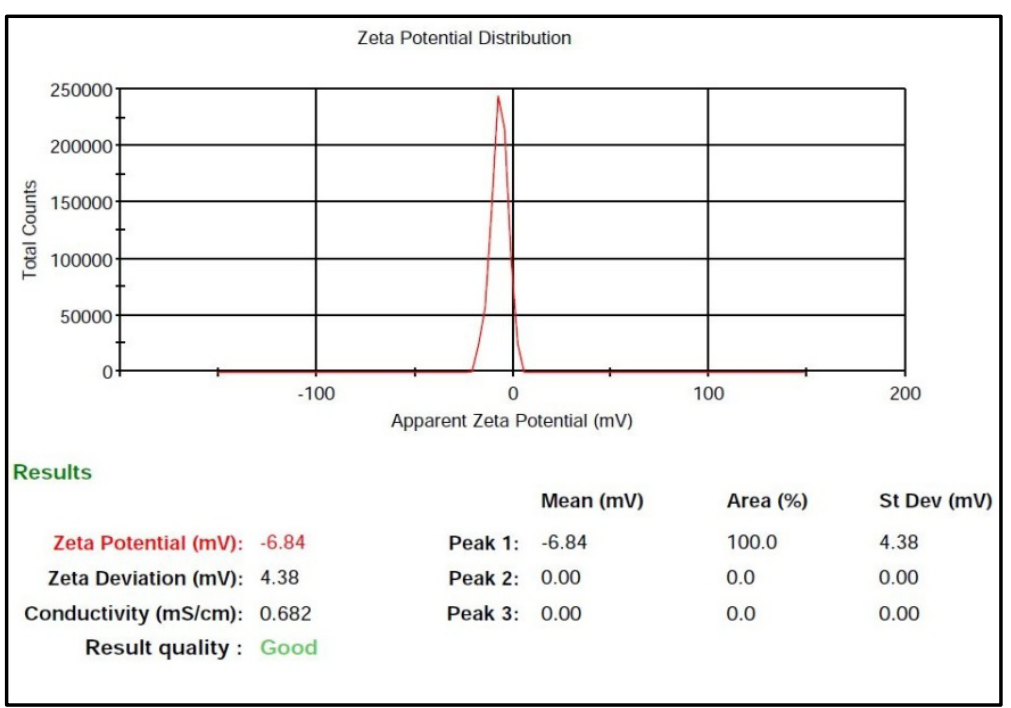

Fig. 4: Zeta potential of optimized SNEDDS formulation 


\section{Zeta potential}

The zeta potential of the optimized batch of SNEDDS was found to be-6.84 mV (fig. 4), which was in the acceptable range of-16 to-32 $\mathrm{mV}$. The zeta potential in the range of -16 to $-32 \mathrm{mV}$ is appropriate to stabilize the prepared formulation.

\section{TEM analysis}

The TEM image clearly showed the droplet size of the optimized formulation and average size was found to be $73.71 \mathrm{~nm}$ (fig. 5).

\section{In vitro antioxidant assay}

Various concentrations ranging from $0.075-0.75 \mathrm{mg} / \mathrm{ml}$ of standard (Ascorbic acid) and formulation were prepared for the activity. The percent inhibition of DPPH by ascorbic acid and SNEDDS was determined (table 4 ) and $\mathrm{IC}_{50}$ values were calculated. The $\mathrm{IC}_{50}$ values for the standard and formulation were recorded as 0.53 $\mathrm{mg} / \mathrm{ml}$ and $0.24 \mathrm{mg} / \mathrm{ml}$, respectively (fig. 6), which clearly showed the improved efficacy of the drug incorporated in SNEDDS.

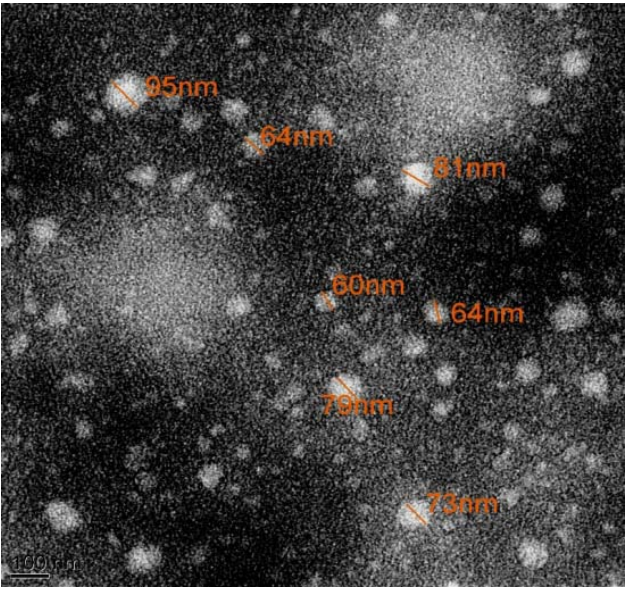

Fig. 5: TEM image of an optimized batch of SNEDDS

Table 4: Percent inhibition of standard and SNEDDS observed in in vitro antioxidant activity

\begin{tabular}{llll}
\hline Concentration (mg/ml) & Log concentration $\mathbf{( m g / m l )}$ & \% inhibition of DPPH (Ascorbic acid) & \% inhibition of DPPH (SNEDDS) \\
\hline 0.075 & -1.12494 & 14.87 & 31.01 \\
0.15 & -0.82391 & 32.27 & 49.05 \\
0.3 & -0.52288 & 41.77 & 52.84 \\
0.45 & -0.34679 & 47.15 & 58.22 \\
0.6 & -0.22185 & 50.94 & 60.75 \\
0.75 & -0.12494 & 55.37 & 65.82 \\
\hline
\end{tabular}

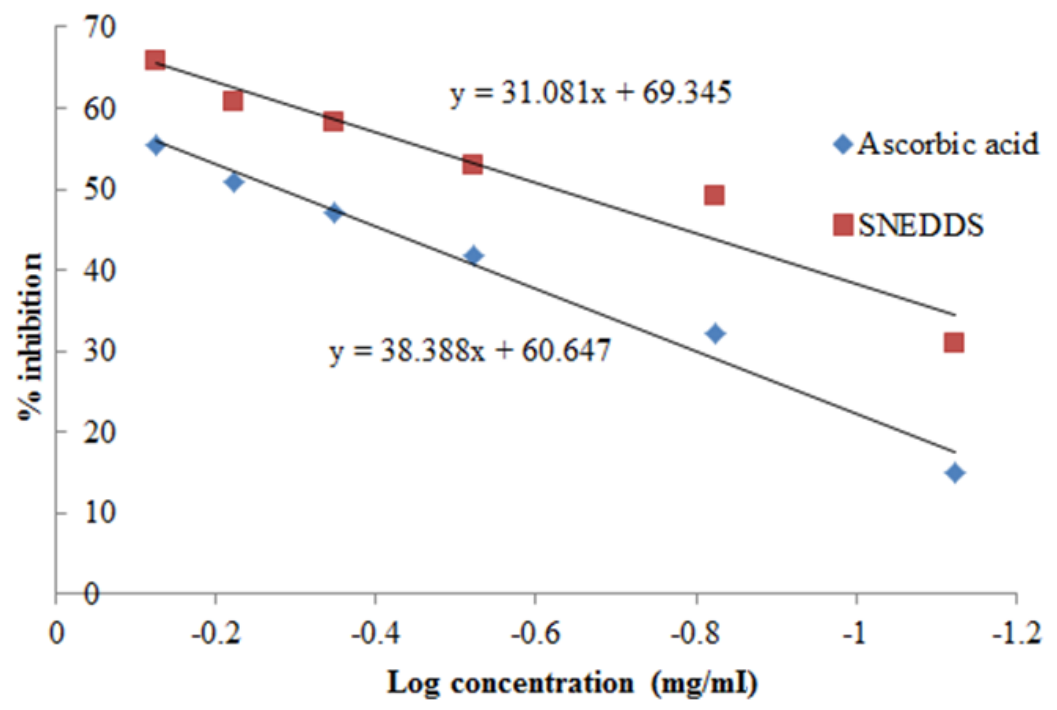

Fig. 6: Semi-log plot of percent inhibition of DPPH

\section{In vitro $\alpha$-amylase inhibition assay}

Different concentrations (0.075-0.75 mg/ml) of standard (Acarbose) and formulation were prepared for in vitro study (table 5). The inhibition observed in different concentrations of standard and
SNEDDS were recorded and IC $_{50}$ values were calculated (table 5). The IC 50 values for acarbose and optimized formulation were found to be $0.064 \mathrm{mg} / \mathrm{ml}$ and $0.091 \mathrm{mg} / \mathrm{ml}$, respectively (fig. 7). The results revealed that formulation has better anti-diabetic activity than standard.

Table 5: Percent inhibition of standard (Acarbose) and SNEDDS observed in in vitro $\alpha$-amylase inhibition assay

\begin{tabular}{llll}
\hline Concentration $(\mathbf{m g} / \mathbf{m l})$ & Log Concentration $\mathbf{( m g / m l )}$ & \% Inhibition of $\boldsymbol{\alpha}$-amylase (Acarbose) & \% Inhibition of $\boldsymbol{\alpha}$-amylase (SNEDDS) \\
\hline 0.075 & -1.12494 & 58.5 & 50.14 \\
0.15 & -0.82391 & 67.76 & 62.53 \\
0.3 & -0.52288 & 74.92 & 90.59 \\
0.45 & -0.34679 & 86.86 & 114.02 \\
0.6 & -0.22185 & 101.34 & 124.47 \\
0.75 & -0.12494 & 110.74 & 139.25 \\
\hline
\end{tabular}




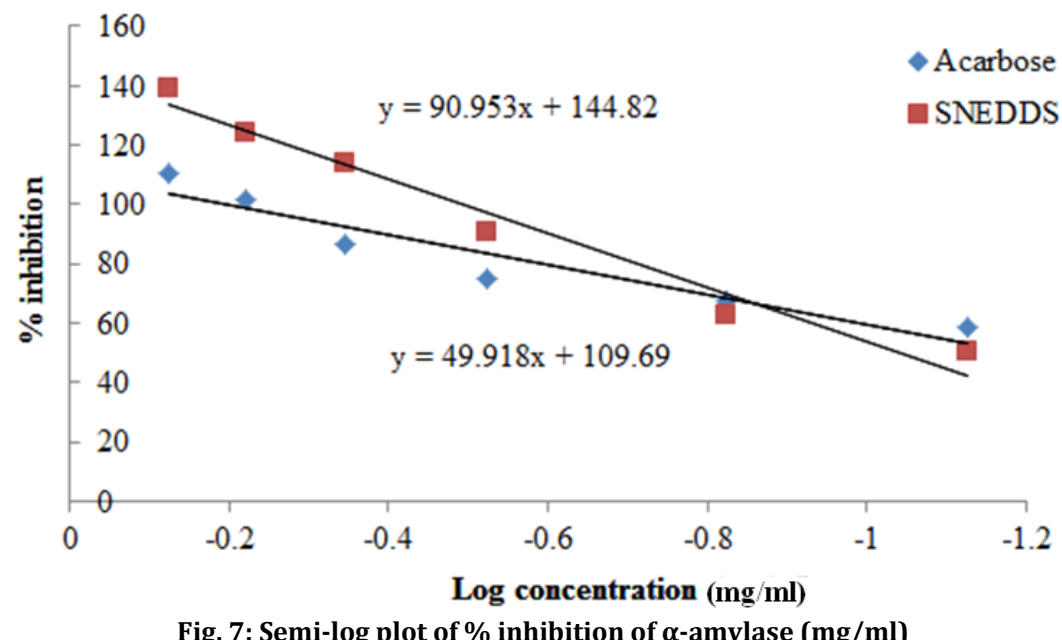

\section{CONCLUSION}

The study revealed the potential application of SNEDDS for improving the dispersity, stability, and bioavailability of plant extracts. Ethanolic extract was prepared from dried leaves of E. japonica and the average yield of the extract was found to be $11.06 \%$. The SNEDDS formulations were prepared by using Labrafil, tween-80, and Transcutol P as oil, surfactant, and co-surfactant, respectively. The optimized design suggested that $10 \%$ of Labrafil M 1944CS, 30\% of Tween 80 and $60 \%$ of Transcutol P can give SNEDDS with $208 \mathrm{~nm}$ mean droplet size, $99.63 \%$ drug loading, $0.156 \mathrm{PDI}$ and $-6 \mathrm{mV}$ zeta potential. TEM image confirmed the nano-size(less than $100 \mathrm{~nm}$ ) and the shape of SNEDDS. In vitro antioxidant and antidiabetic activities of SNEDDS were observed to be comparable with ascorbic acid and acarbose, respectively, which revealed the potential of SNEDDS formulation in diabetes management.

\section{AUTHORS CONTRIBUTIONS}

The authors declare that this work was performed by all authors named in this article, and all liabilities pertaining to claims relating to the content of this article will be borne by all of them. All authors approved and read the manuscript for publication.

\section{CONFLICT OF INTERESTS}

The authors have declared no conflict of interest

\section{REFERENCES}

1. Anju K, Jegadeeshwari AL, Gandhi NN. Optimization of green synthesized silver nanoparticles from Caralluma umbellate. Int J Appl Pharm 2018;10:103-10.

2. Al-Nemrawi NK, Alsharif SSM, Dave RH. Preparation of chitosan-TPP nanoparticles: the influence of chitosan polymeric properties and formulation variables. Int J Appl Pharm 2018;10:60-5.

3. Shiyan S, Herlina H, Rizkika Sari L. Nephroprotective of anthocyanin pigments extract from red cabbage (Brassica oleracea L. Var. Capitata f. Rubra) against gentamicin-captopril-induced nephrotoxicity in rats. Asian J Pharm Clin Res 2018;11:432-6.

4. Kalva S, Raghunandan N. Preliminary phytochemical screening and antimicrobial activity of dried flowers of Adenium obesum. Int J Curr Pharm Res 2019;11:34-6.

5. Zhang L, Zhang L, Zhang M, Pang Y, Li Z, Zhao A, et al. Selfemulsifying drug delivery system and the applications in herbal drugs. Drug Delivery 2015;22:475-86.

6. Noreen W, Wadood A, Hidayat HK, Wahid SA. Effect of Eriobotrya japonica on blood glucose levels of normal and alloxan-diabetic rabbits. Planta Med 1988;54:196-9.

7. Kim MJ, Lee J, Seong AR, Lee YH, Kim YJ, Baek HY, et al. Neuroprotective effects of Eriobotrya japonica against Bamyloid-induced oxidative stress and memory impairment. Food Chem Toxicol 2011;49:780-4.
8. Tanaka K, Tamaru S, Nishizono S, Miyata Y, Tamaya K, Matsui T, et al. Hypotriacylglycerolemic and antiobesity properties of a new fermented tea product obtained by tea-rolling processing of thirdcrop green tea (Camellia sinensis) leaves and loquat (Eriobotrya japonica) leaves. Biosci Biotechnol Biochem 2010;74:1606-12.

9. Kotowaroo MI, Mahomoodally MF, Gurib-Fakim A, Subratty AH. Screening of traditional antidiabetic medicinal plants of mauritius for possible $\alpha$-amylase inhibitory effects in vitro. Phytother Res 2006;20:228-31.

10. Shih CC, Ciou JL, Lin CH, Wu JB, Ho HY. Cell suspension culture of Eriobotrya japonica regulates the diabetic and hyperlipidemic signs of high-fat-fed mice. Molecules 2013;18:2726-53.

11. Choi YG, Seok YH, Yeo S, Jeong MY, Lim S. Protective changes of inflammation-related gene expression by the leaves of Eriobotrya japonica in the LPS-stimulated human gingival fibroblast: a microarray analysis. J Ethnopharmacol 2011;135:636-45.

12. Alshaker HA, Qinna NA, Qadan F, Bustami M, Matalka KZ. Eriobotrya japonica hydrophilic extract modulates cytokines in normal tissues, in the tumor of Meth-A-fibrosarcoma bearing mice, and enhances their survival time. BMC Complement Altern Med 2011;11:9.

13. Kang SC, Lee $\mathrm{CM}$, Choi $\mathrm{H}$, Lee JH, Oh JS, Kwak JH, et al. Evaluation of oriental medicinal herbs for estrogenic and antiproliferative activities. Phytother Res 2006;20:1017-9.

14. Yokota J, Takuma D, Hamada A, Onogawa M, Yoshioka S, Kusunose $\mathrm{M}$, et al. Scavenging of reactive oxygen species by Eriobotrya japonica seed extract. Biol Pharm Bull 2006;29:467-71.

15. Wu G, Chai J, Suber TL, Wu JW, Du C, Wang X, et al. Structural basis of IAP recognition by Smac/DIABLO. Nature 2000;408:1008-12.

16. Uysal S, Zengin G, Aktumsek A, Karatas S. Fatty acid composition, total sugar content and anti-diabetic activity of methanol and water extracts of nine different fruit tree leaves collected from mediterranean region of turkey. Int J Food Prop 2015;18:2268-76.

17. Shafiq S, Shakeel F, Talegaonkar S, Ahmad FJ, Khar RK, Ali M. Development and bioavailability assessment of ramipril nanoemulsion formulation. Eur J Pharm Biopharm 2007;66:227-43.

18. Ujilestari T, Ariyadi B, Martien R, Zuprizal, Dono N. Optimization of self-nano emulsifying drug delivery systems of lemongrass (Cymbopogon citratus) essential oil. Int J Appl Pharm 2019;11:144-9.

19. Jain PK, Khurana N, Pounikar Y, Gajbhiye A, Kharya MD. Enhancement of absorption and hepatoprotective potential through the soya-phosphatidylcholine-andrographolide vesicular system. J Liposome Res 2013;23:110-8.

20. Katoch P, Kaur P, Singh R, Vyas M, Singh SK, Gulati M. Development and characterization of self-nanoemulsifying drug delivery system loaded with fixed oil of Semecarpus anacardium Linn. Asian J Pharm 2016;10:144-53. 
21. Preethi G, Shivakumar H, Kumar M, Sweta N. Prototype self smulsifying system of Etravirine: Design, formulation and in vitro evaluation. Int J Appl Pharm 2018;10:13-9.
22. Sah A, Raj S, Khatik G, Vyas M. Nutritional profile of spinach and its antioxidant and antidiabetic evaluation. Int J Green Pharm 2017;11:192-7. 